\title{
Estudo
}

de caso

\section{O projeto}

Plano de ação

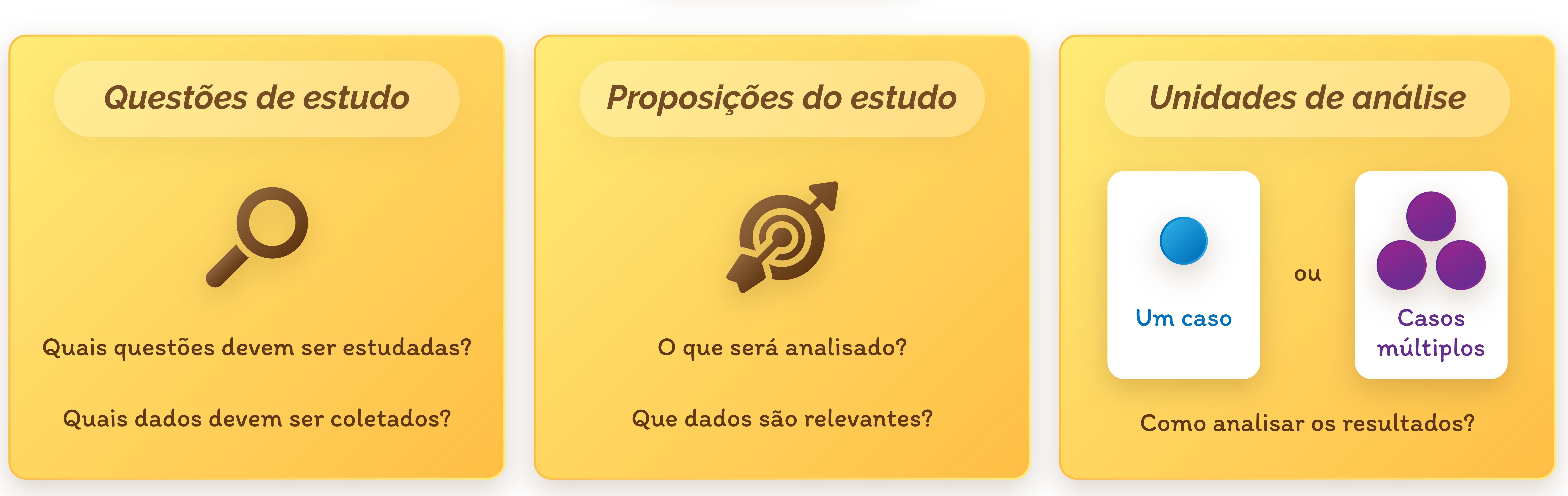

Lógica de ligação dos dados às proposiçōes e aos critérios para a interpretação das descobertas.

Desenvolvimento do estudo de caso

Etapas dos dados
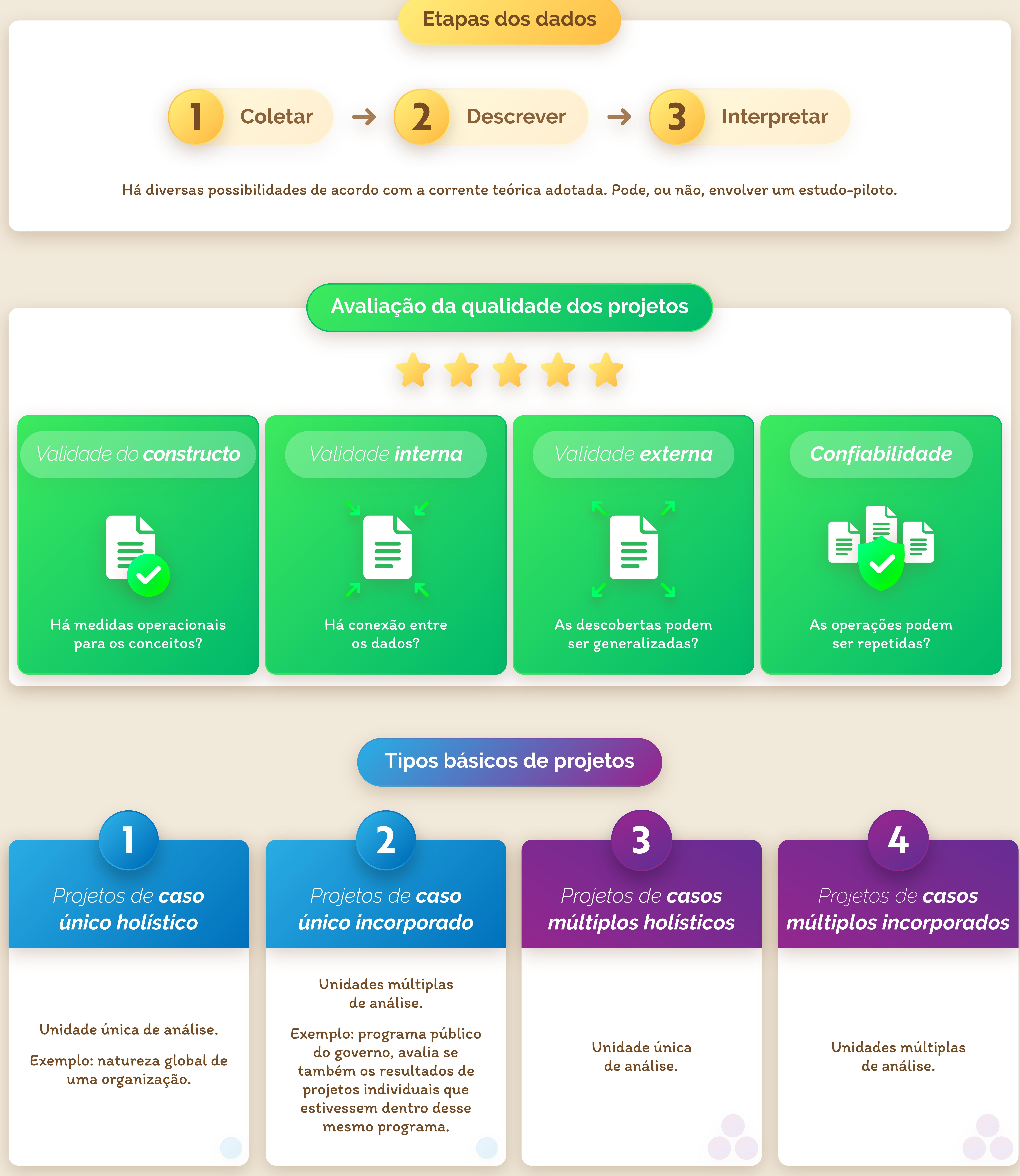

Um projeto e holistico quando náo è possivel identificar uma subunidade e a teoria e holistica.

Coleta de evidências

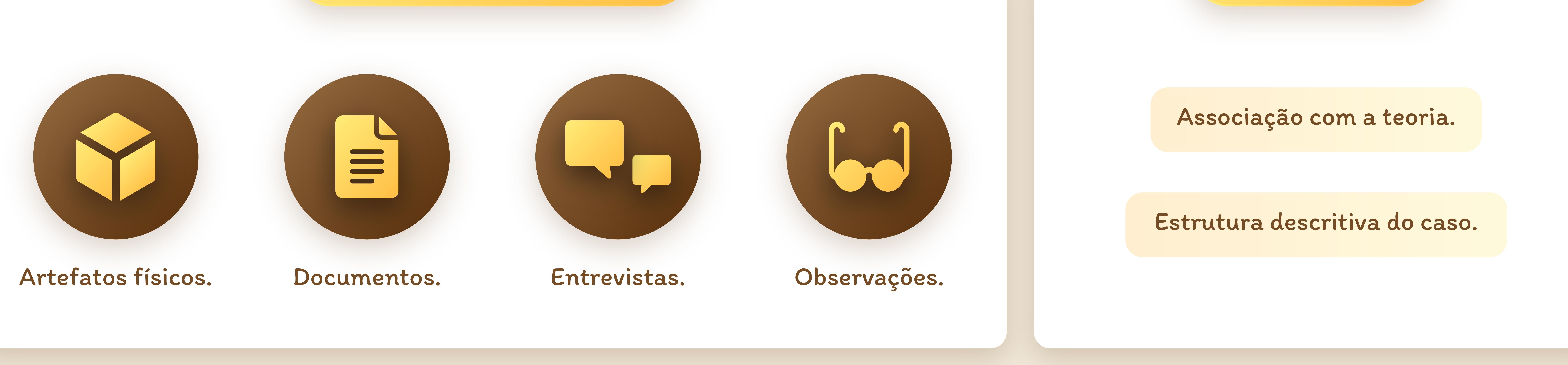

Principais métodos de análise
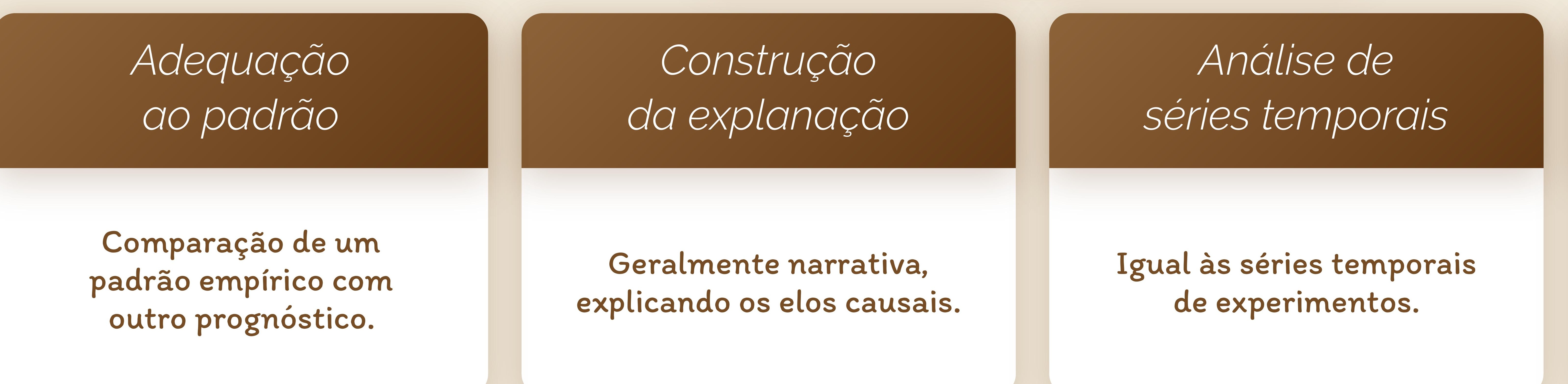

Modelos lógicos

e programa

Comparação de um

padras empirice com
outro prognostico.

Geralmente narrativa,

explicando os elos causais

gual às séries temporais

Combiną̧ão 